\title{
Medicinal cannabis: Time to lighten up?
}

\author{
David N. Juurlink MD PhD
}

See related commentary on page 895 and at www.cmaj.ca/lookup/doi/10.1503/cmaj.131821

$\mathrm{H}$ ave you ever talked to your family physician about medical marijuana?" I recently asked this question of a patient for the first time in 20 years as a physician. The novelty of it sticks with me, as does a trace of guilt for deflecting the real discussion to another doctor, one who might not be prepared to have it. (I consulted on the patient in hospital and am unlikely to see him again.) But I believe that endorsing the use of medicinal cannabis for this patient was the right thing to do.

There are many reasons why considering prescribing cannabis might make a physician uneasy. Its efficacy has not been properly established for many conditions, and legitimate safety questions exist, largely because the drug is illegal in most jurisdictions. Many physicians have no idea how to write a prescription for cannabis. Furthermore, the dose of cannabinoids received by the patient for a given prescription will vary according to factors beyond our control. Some physicians may harbour a reluctance to be "the doc who writes scripts for weed," possibly attracting patients with ulterior motives. For most indications, physicians have more familiar prescription medications at our disposal.

Yet a case can be made for the judicious prescribing of cannabis, particularly for patients who have previously experienced meaningful symptomatic improvement with its use, and for those who have not benefited from or are intolerant of conventional medications. The strongest argument in favour of medicinal cannabis rests in one of the most fundamental objectives of medicine: the relief of suffering, which is always best done in a patient-specific context and with due consideration of the drugs we might otherwise prescribe. At issue here is the overarching goal of drug therapy.

Every prescription we write should meet two objectives. First, it should be issued with the intent of making the patient feel better, live longer or both. A prescription that carries no realistic prospect of either should not be written.
Second, a drug's expected benefits should exceed its risks, ideally by a large margin. These criteria are so intuitive and irrefutable that one might argue they need not be explicitly stated. Yet they do, because many of our prescriptions violate one or both of them.

Consider a patient with chronic pain who tells his physician that he has used cannabis, that it lessens his pain or makes it more tolerable and that he prefers it to other analgesics. On what grounds would his physician deny him this option? The easiest way would be to cite the lack of evidence for medical cannabis or express concerns about its safety, ${ }^{1}$ but the logic in this approach is weak. First, many analgesics we might prescribe instead of cannabis are themselves not supported by robust evidence, having been evaluated against placebo in studies of short duration that used "pain scales" rather than clinically meaningful outcomes. ${ }^{2,3}$ The notion that they constitute evidence-based therapies on that basis is tenuous at best.

In contrast, a patient who reports meaningful relief with cannabis arms his physician with evidence applicable directly to himself. Some may criticize this as anecdote-based medicine, but our prescribing is influenced every day by patients' reports of subjective response. We interpret these reports as a type of personalized medicine, and rightly so. It is difficult to craft a logical argument as to why we should dismiss anecdotes about symptomatic improvement from cannabis while accepting them about, for example, oxycodone or fentanyl.

\section{- Ker pOINTS}

- Opposition to the prescribing of cannabis by physicians is based primarily on limited evidence of its safety and effectiveness.

- Many drugs that might be prescribed instead of cannabis are not themselves supported by robust evidence of benefits exceeding harms.

- A pragmatic case can be made for the judicious prescribing of cannabis to patients who report meaningful benefit from it, especially when its use minimizes the need for other medications that carry risk. 
The safety argument against cannabis falters here too. More research is clearly needed on the adverse effects of cannabis, and smoked cannabis in particular. ${ }^{4.5}$ (Nabilone and nabiximols, pharmaceutical cannabinoids licensed for use in Canada, are devoid of respiratory effects.) However, from a pharmacologic perspective, the direct toxic effects of cannabinoids are simply dwarfed by those of opioids and nonsteroidal anti-inflammatory drugs. Many patients are injured or die every year from the medications we prescribe for pain. ${ }^{6.8}$ Although dependence and withdrawal symptoms can occur in heavy cannabis users, these phenomena are more common and far more consequential in patients who receive opioids. ${ }^{9}$

Similar arguments for the judicious prescribing of cannabis for chronic pain may extend to other conditions. I return to the patient described at the beginning of the article, a man with a longstanding history of anxiety, work-related stress and financial difficulties. In the weeks before we met, he had started treatment with an antidepressant, and treatment-emergent suicidality developed. ${ }^{10}$ After surviving a drug overdose, he recounted years of intolerance and nonresponse to almost every class of psychotropic drug. In our lengthy discussion, he also shared that the only time he felt at peace was in the evening, when, with his wife's blessing, he would take his dog for a walk and smoke a joint. Although his problems remained, the stresses that dogged him throughout the day evaporated, and he was able to return home to a good night's sleep.

This was a revelatory clinical encounter for me. Here was an intelligent man with a home, a family and a habit that will likely become legal in Canada, who was numbed by psychotropic drugs. His suicide attempt was, I believe, triggered by the antidepressant. Not only was he articulating that the conventional psychotropic drugs he had received did not alleviate his suffering, he was telling me what did. This was anecdote of the sort that I could not in good conscience dismiss.
The discussion about medicinal cannabis is one our patients will bring to us whether we want it or not. As physicians, we should not reject cannabis as a medicine simply because it makes us uncomfortable, or invoke concerns about effectiveness and safety without acknowledging that the other drugs we might prescribe carry similar and often much heavier baggage. Nor should we accede to every request for medicinal cannabis as if it were an innocuous panacea. It is not. Instead, we should do what we do every day: make treatment decisions in a patient-specific context, after balancing the risks and benefits of the available options. If we do that thoughtfully, prescribing cannabis will sometimes be the right thing to do.

\section{References}

1. Lynch ME, Campbell F. Cannabinoids for treatment of chronic noncancer pain; a systematic review of randomized trials. $\mathrm{Br} \mathrm{J}$ Clin Pharmacol 2011;72:735-44.

2. Chou R, Ballantyne JC, Fanciullo GJ, et al. Research gaps on use of opioids for chronic noncancer pain: findings from a review of the evidence for an American Pain Society and American Academy of Pain Medicine clinical practice guideline. J Pain 2009;10:147-59.

3. Kissin I. Long-term opioid treatment of chronic nonmalignant pain: Unproven efficacy and neglected safety? J Pain Res 2013;6:513-29.

4. Joshi M, Joshi A, Bartter T. Marijuana and lung diseases. Curr Opin Pulm Med 2014;20:173-9.

5. Rathbone J, Variend H, Mehta H. Cannabis and schizophrenia. Cochrane Database Syst Rev 2008;(3):CD004837.

6. Dhalla IA, Persaud N, Juurlink DN. Facing up to the prescription opioid crisis. BMJ 2011;343:d5142.

7. Mamdani M, Rochon PA, Juurlink DN, et al. Observational study of upper gastrointestinal haemorrhage in elderly patients given selective cyclo-oxygenase- 2 inhibitors or conventional non-steroidal anti-inflammatory drugs. BMJ 2002;325:624.

8. Mamdani M, Juurlink DN, Lee DS, et al. Cyclo-oxygenase-2 inhibitors versus non-selective non-steroidal anti-inflammatory drugs and congestive heart failure outcomes in elderly patients: a population-based cohort study. Lancet 2004;363:1751-6.

9. Juurlink DN, Dhalla IA. Dependence and addiction during chronic opioid therapy. J Med Toxicol 2012;8:393-9.

10. Teicher MH, Glod CA, Cole JO. Antidepressant drugs and the emergence of suicidal tendencies. Drug Saf 1993;8:186-212.

Affiliations: Sunnybrook Research Institute; Departments of Medicine and Pediatrics, University of Toronto, Toronto

Acknowledgements: The author thanks Irfan Dhalla, Moira Kapral, David Nutt, Jeremy Petch, Donald Redelmeier and Mark Ware for their comments on an earlier draft of this commentary.

\section{Call for papers: CMAJ Holiday Reading}

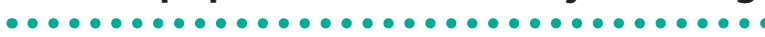

'Twas months before the holidays and all through CMAJ house not a submission was stirring, making editors grouse. "Holiday Reading time is nigh!" they cried in despair, in hopes that your papers soon would be there.

Submit your brilliant missives, rigorous research (based on real data) on quirky topics or holiday-themed visuals at http://mc.manuscriptcentral.com/cmaj. Nonresearch submissions should be no longer than 1200 words. For information, contact kelly.clarke@cmaj.ca.

Deadline: October 1, 2014

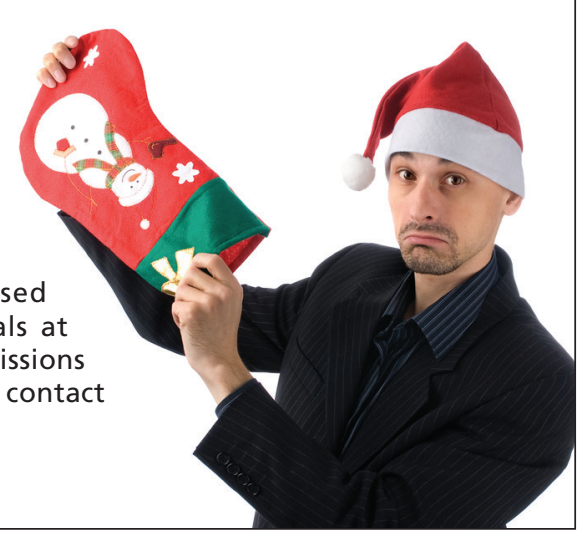

